\title{
EL IVA: EXPECTATIVAS Y CAMBIOS NECESARIOS
}

\author{
Pablo Antonio Moreno Valero
}

Doctor en Economía. Profesor Adjunto Universidad San Pablo CEU. Facultad de Derecho. Departamento de Derecho Financiero y Tributario España.

E-mail: pablo.morenovalero@ceu.es

\section{Resumen}

El IVA es un impuesto comunitario y una de sus características tiene como objetivo introducir un sistema común. Este artículo plantea que el nuevo régimen del IVA deberá garantizar el control de la imposición y considerar las transacciones intracomunitarias equivalentes a las internas. Por consiguiente, es necesario establecer un sistema de compensación que acompañe a la implantación de un principio de gravamen en origen.

Palabras clave: Impuesto comunitario, sistema común, principio de gravamen en origen, sistema de compensación

\begin{abstract}
VAT is a Community tax and it's trying to introduce a new common system. This article sets forth that the new VAT regime must guarantee the taxation control, considering the intracommunity transactions as a internal ones. Therefore, it's necessary create an origin taxation system accompanied by a compensation system.
\end{abstract}

Key Word: Community tax / common system / origin taxation system / compensation system

\section{Résumé}

La TVA est un impôt européen et une caractéristique vise à introduire un système commun. Cet article soutient que le nouveau système de TVA doit vérifier et d'examiner l'imposition de transactions intracommunautaires équivalentes aux détenus. Il est donc nécessaire d'établir un système de compensation qui accompagnent la mise en œuvre

d'un principe de l'imposition à la source.

Mots-clés: L'impôt communautaire, système commun de taxation au principe de la source, régime d'indemnisation 

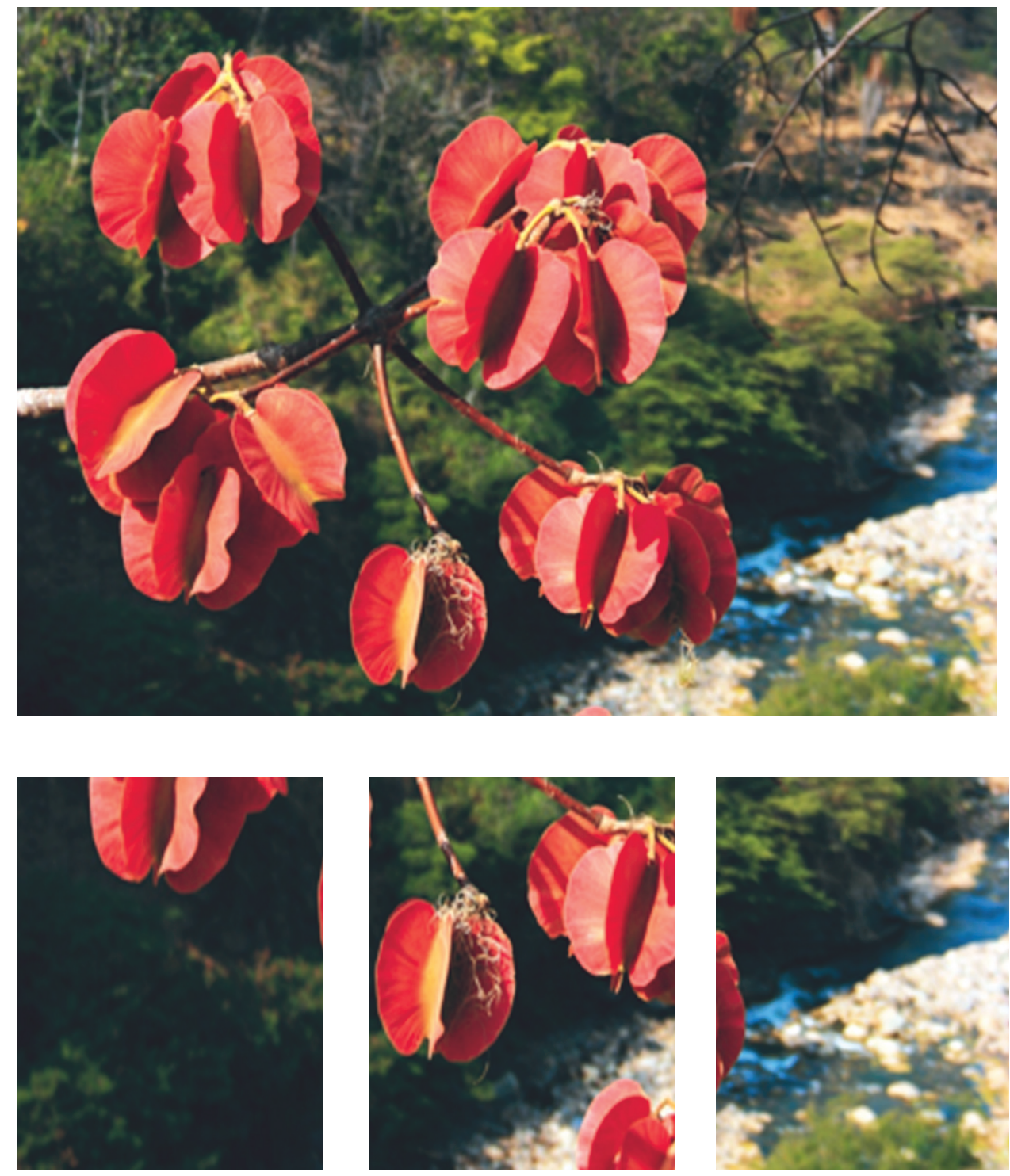

Cañón del Chicamocha - Ceibas Barrigonas

Jorge William Sánchez Latorre 


\section{EI IVA: EXPECTATIVAS Y CAMBIOS NECESARIOS}

Pablo Antonio Moreno Valero

\section{CONSIDERACIONES PREVIAS}

En 1954 el Ministro de Finanzas francés, Maurice Lauré, convierte a su país en el primero en aplicar el IVA. Este "impuesto sobre el valor añadido" recae sobre el consumidor final, proporcional al precio del bien o servicio, no considerado el número de intermediarios hasta llegar al último eslabón de la cadena.

En 1957 a través del Tratado de Roma se constituye la entonces denominada Comunidad Económica Europea. Uno de sus objetivos fundamentales, recogidos en el actual artículo 14 del Tratado de la Comunidad Europea, era el de crear un mercado único en el que se garantizara la libre circulación de bienes y servicios.

Para poder hacer realidad la libre circulación de bienes y servicios se creó una tarifa aduanera común. Lo verdaderamente necesario era crear un sistema impositivo único para poder llevar a la práctica un intercambio de bienes y servicios entre Estados miembros. Fue esencial llevar a cabo una armonización fiscal a nivel comunitario para así poder establecer un sistema común de imposición en relación al Impuesto sobre el Valor Añadido, impuesto que grava las entregas de bienes y prestaciones de servicios.

El Reglamento 92/218/CEE de 27 de enero estableció la cooperación que debe darse entre las Administraciones Tributarias de los Estados miembros, es objeto de desarrollo normativo en nuestro ordenamiento interno por medio del Real Decreto 1624/1992, de 29 de diciembre, por el que se aprueba el Reglamento del IVA.

Por otro lado, en 1977 se publica la primera norma básica de transcendencia comunitaria en este ámbito: la Sexta Directiva del Consejo 77/388/CE, de 17 de mayo de 1977. Ésta es la norma más importante en materia de armonización de legislaciones

* Registro de Clasificación JEL: H24, H87. En el marco del proyecto de investigación, el presente artículo reflexiona sobre la propuesta de: establecer un sistema de compensación en la implementación del gravamen en el nuevo régimen con ello el IVA, deber garantizar el control de la imposición y considerar las transacciones intracomunitarias equivalentes a las internas. 
de los Estados miembros, relativa al IVA. Con ella quedaron establecidas las reglas básicas y uniformes para la determinación de una base imponible común.

Pero es en 1993 cuando se creó efectivamente el mercado interior y se consiguió avanzar en la armonización del IVA. En esta fecha se eliminaron definitivamente las fronteras fiscales y se estableció el principio básico que debería inspirar todo el sistema: el principio de tributación en origen. La razón del cambio con respecto al sistema anterior, el de tributación en destino, implicó la creación de un hecho imponible nuevo, tal y como viene señalado en la Exposición de Motivos de la Ley 37/92 del IVA

"la abolición de las fronteras fiscales supone la desaparición de las importaciones entre los Estados miembros, por tanto, este nuevo hecho imponible se configura como la obtención del poder de disposición, efectuada por un sujeto pasivo o persona jurídica que no actúe como tal, sobre un bien mueble corporal objeto de una transmisión realizada por un sujeto pasivo, siempre que dicho bien se expida o transporte de un Estado miembro a otro".

El problema de este sistema es que los Estados miembros netamente importadores pierden una parte de su recaudación por IVA a favor de aquellos Estados con un volumen de exportaciones superior al de las importaciones.

La parte negativa es que el desarrollo de las libertades fundamentales del mercado interior, además de generar un beneficioso efecto económico, ha facilitado las operaciones de fraude y elusión fiscal en los Estados miembros. Por esta razón, se ha intentado remediar a través de la cooperación entre administraciones tributarias de los Estados miembros, y con ciertas modificaciones legales, como es el caso de la Directiva 2008/117/CE.

\section{DE LA SEXTA DIRECTIVA -IVA- A LA REGULACIÓN ACTUAL}

Con la aprobación de la Sexta Directiva en 1977 se mantuvo, aunque, con carácter transitorio, el tradicional principio de imposición en destino de las transacciones internacionales. Esto implicó el mantenimiento del procedimiento de ajustes fiscales en frontera.

No cabe duda que la aprobación de la Sexta Directiva constituye la aprobación de la norma más importante en materia de armonización fiscal en el IVA, pues con ella quedaron establecidas las reglas básicas y uniformes para la determinación de una base imponible común, que era necesaria para fijar la participación de la Comunidad en la recaudación del IVA en los Estados miembros.

La idea era llegar a conseguir modificar el sistema hasta alcanzar el principio de tributación en origen, pero, a pesar de las modificaciones que se han producido a lo largo de los años, no se ha podido lograr este objetivo. Por el momento, ha sido 
imposible la creación de un sistema de compensación, que permita que las cuotas repercutidas e ingresadas en un país miembro en concepto de exportación sean devueltas al resto de los Estados miembros en los que las cuotas impositivas van a ser deducidas y en los que va a tener lugar el consumo final del bien o servicio.

Esta Directiva fue modificada de forma sustancial en numerosas ocasiones. Por esta razón, en aras de la claridad y la racionalización, se procedió a la refundición de dicha Directiva, dando como resultado la Directiva 2006/112/CE. ${ }^{1}$

Para un análisis pormenorizado de la misma, hay que poner de manifiesto sus aspectos más relevantes.

\section{Ámbito de aplicación (artículos 1 a 4 de la Directiva del IVA)}

Están sujetas al IVA las operaciones efectuadas a título oneroso en el territorio de un Estado miembro por un sujeto pasivo que actúe como tal. También están sujetas al IVA las importaciones efectuadas por cualquier persona.

Los hechos imponibles incluyen:

- las entregas de bienes por un sujeto pasivo

- las adquisiciones intracomunitarias en un Estado miembro de bienes procedentes de otro Estado miembro

- las prestaciones de servicios por un sujeto pasivo

- las importaciones de bienes procedentes del exterior de la CE (un territorio tercero o un país tercero)

Una adquisición intracomunitaria de bienes únicamente se produce cuando hay transporte de bienes entre Estados miembros diferentes. Se efectúa cuando los bienes vendidos por un sujeto pasivo en el Estado miembro de partida son adquiridos en otro Estado miembro de llegada por un sujeto pasivo que actúe como tal, o por una persona jurídica no sujeta al impuesto. Tiene lugar también cuando se trata de medios de transporte nuevos y de productos sujetos a impuestos especiales adquiridos por otras personas.

\section{Hecho imponible (Título IV)}

La entrega de bienes es la transmisión del poder de disposición sobre un bien corporal con las facultades atribuidas a su propietario.

Se consideran "prestaciones de servicios" todas las operaciones que no constituyen una entrega de bienes.

1 Directiva 2006/112/CE Consideración 5: Por lo tanto, es necesario lograr una armonización de las legislaciones en materia de impuestos sobre el volumen de negocios mediante un régimen de impuesto sobre el valor añadido, en adelante IVA, con objeto de eliminar, en la medida de lo posible, y tanto en el plano nacional como en el plano comunitario, los factores susceptibles de falsear las condiciones de competencia. 
La adquisición intracomunitaria de bienes es la obtención del poder de disposición como propietario de un bien mueble corporal expedido o transportado con destino al adquiriente en un Estado miembro distinto del de partida.

La importación de bienes es la introducción en la CE de un bien que no esté en libre práctica. La introducción de un bien en libre práctica procedente de un territorio tercero es también una importación.

\section{Devengo y exigibilidad del impuesto (Título VI)}

El devengo del impuesto (el hecho mediante el cual quedan cumplidas las condiciones legales precisas para la exigibilidad del impuesto) se produce, y el impuesto se hace exigible (el derecho que el Tesoro Público puede hacer valer, en los términos fijados en la Ley y a partir de un determinado momento, ante el deudor para el pago del impuesto, incluso en el caso de que el pago pueda aplazarse), en el momento en que se efectúa la entrega de bienes o la prestación de servicios, salvo en determinados casos enumerados específicamente.

En el caso de las adquisiciones intracomunitarias de bienes, el impuesto se devenga en el momento en que se efectúa la adquisición. El impuesto será exigible el día 15 del mes siguiente a la adquisición. Si se expide una factura antes de esa fecha, el impuesto será exigible en el momento de la expedición de esta factura.

En cuanto a la importación de bienes, el devengo del impuesto se produce, y el impuesto es exigible, en el momento en que el bien se introduce en el interior de un Estado miembro de la $\mathrm{CE}$

\section{Base imponible (Título VII)}

En el caso de las entregas y las adquisiciones intracomunitarias de bienes y las prestaciones de servicios, la base imponible está constituida por la totalidad de la contraprestación que quien realice la entrega o preste el servicio obtenga, por estas operaciones, del adquiriente, incluidas las subvenciones directamente vinculadas al precio de estas operaciones. La base incluye también los impuestos, derechos, tasas y exacciones parafiscales (con excepción del propio IVA) y los gastos accesorios exigidos por el proveedor al adquiriente, pero no incluye determinadas disminuciones de precio, rebajas y descuentos de precio, ni las sumas recibidas en reembolso de los gastos soportados.

En las importaciones de bienes, la base imponible está constituida por el valor definido como valor en aduana. Los impuestos, derechos, exacciones y demás gravámenes que se devenguen fuera del Estado miembro de importación, así como los que se devenguen con motivo de la importación (excepto el IVA que haya de percibirse) y los gastos accesorios (embalaje, transporte y demás) deben incluirse en la base imponible. 


\section{Tipos (Título VIII)}

\section{El artículo 96 prevé que}

"Los Estados miembros aplicarán un tipo impositivo normal de IVA, fijado por cada Estado miembro en un porcentaje de la base imponible que será el mismo tanto para las entregas de bienes como para las prestaciones de servicios y el 98 establece que los Estados miembros podrán aplicar uno o dos tipos reducidos. 2. Los tipos reducidos se aplicarán únicamente a las entregas de bienes y a las prestaciones de servicios de las categorías que figuran en el anexo III".

Es relevante la dicción literal de este artículo, en aras a entender lo que más tarde va ser objeto de debate en el seno de la UE, en cuanto a tipos reducidos se refiere. Así, se ha de mencionar una propuesta de la Comisión de 2007 en la que se aborda la posibilidad de modificar dicho Anexo III de la Directiva del IVA ${ }^{2}$. No obstante, dicha modificación va a tener varios horizontes temporales, unos a medio plazo, en el que se va a pretender una respuesta equilibrada a la aplicación de los tipos, y otro, más a corto plazo $^{3}$, en el que se pretenden dirimir los problemas que han surgido de la aplicación de la Directiva del IVA.

Basándose en el estudio sobre los tipos reducidos del IVA aplicados a bienes y servicios en los Estados miembros de la Unión Europea, presentado por Copenhagen Economics (en lo sucesivo «el estudio CE»), el 5 de julio de 2007, la Comisión aprobó una Comunicación sobre los tipos del IVA distintos del tipo normal (COM (2007) 380; en lo sucesivo «la comunicación de 2007»), en la que se exploraban posibles vías de futuro en el ámbito de los tipos reducidos del IVA y que pretendía servir de punto de partida de un amplio debate político en las demás instituciones comunitarias y con todos los interesados.

El estudio de Copenaghen Economics ${ }^{4}$ contiene importantes consideraciones:

2 Para que los Estados Miembros puedan aplicar tipos reducidos del IVA a determinados servicios de ámbito local, incluidos los servicios de gran intensidad de mano de obra y los de restauración. Se incluyen también en esta propuesta algunas adaptaciones técnicas.

3 La Comisión presenta una propuesta legislativa limitada que modifica lo dispuesto en la Directiva 2006/112/CE, de 28 de noviembre de 2006 (en lo sucesivo «la Directiva del IVA», en relación con asuntos urgentes que no requieren ningún estudio complementario sustancial, aparte del que se menciona en su comunicación y que se detalla en el documento de trabajo de los servicios de la Comisión (SEC (2007) 910). Esta propuesta debe, en principio, considerarse una primera medida en lo relativo a los tipos reducidos del IVA.

4 COM (2007) 380 final. Apartado 2. Principales Conclusiones del estudio sobre el impacto de tipos reducidos: El estudio subraya que un único tipo de IVA es, de lejos, la mejor opción estratégica desde un punto de vista puramente económico. No obstante, aplicar un IVA reducido puede reportar ventajas específicas a sectores muy concretos. La creación de empleo poco cualificado en estos sectores relativamente reducidos queda, por tanto, prácticamente neutralizada por la pérdida de empleo en otros sectores donde se aplica un tipo de IVA más elevado. Para mejorar la distribución de la renta en un Estado miembro, los tipos reducidos del IVA solamente son eficaces cuando la parte de los gastos de consumo en bienes/servicios sujetos a un tipo reducido (en relación con el 
A partir del estudio CE, la Comisión considera a lo largo de la Comunicación que cabe otorgar una mayor autonomía y conferir mayor seguridad a los Estados miembros a la hora de someter determinados servicios locales a tipos reducidos, en consonancia con la labor destinada a mejorar el entorno en el que operan las PYME, que es una de las actuaciones prioritarias con arreglo a la Estrategia de Lisboa para el Crecimiento y el Empleo, y en particular con la Ley de la Pequeña Empresa. La Comisión5 considera que la estructura actual de tipos del IVA, resulta ineficaz desde la perspectiva del mercado interior y de la competitividad global de las empresas de la UE es necesaria una nueva arquitectura de tipos reducidos del IVA en la Comunidad que tuviera en consideración objetivos tales como:

- La necesidad de garantizar la igualdad de trato entre todos los Estados miembros, lo que implica el fin de las exenciones específicas de cada país;

- El reconocimiento de que, en la mayor parte de los Estados miembros, existe una fuerte voluntad política de aplicar tipos muy reducidos, incluso nulos, particularmente con fines sociales;

- El reconocimiento de las dificultades (económicas y presupuestarias) cada vez mayores de los Estados miembros para transferir productos de una categoría de tipos a otra, a causa de la diferencia, con frecuencia muy importante, entre el tipo normal y un tipo reducido (en la mayoría de los casos superior a 10 puntos e incluso a 15 );

- La necesidad de establecer una lógica clara de los fines para los que debe utilizarse un tipo reducido;

- La necesidad de equilibrar la mayor flexibilidad con una reducción de los costes de cumplimiento.

Una de las maneras de llevar estos objetivos a la práctica podría ser: prever un tipo muy bajo para bienes y servicios de primera necesidad, como los productos alimenticios; obviamente, el debate sobre el ámbito de aplicación de este tipo reducido será difícil (¿deben incluirse los tratamientos médicos y la vivienda social, entre otros), pero permitiría limitar su aplicación (y su coste) a las necesidades básicas reales de los ciudadanos y tener en cuenta de esta forma consideraciones exclusivamente sociales; además, podría utilizarse un segundo tipo con otros fines, distintos de las

total de los gastos de consumo) es suficientemente diferente entre los grupos con ingresos bajos y elevados y se mantiene estable en el tiempo. Los tipos reducidos del IVA generan importantes costes de cumplimiento para las empresas y las autoridades fiscales. El estudio recomienda que los Estados miembros examinen cuidadosamente todas las opciones disponibles cuando deseen fomentar el consumo de bienes o servicios específicos: con frecuencia, otros instrumentos resultan más eficaces y menos onerosos para los presupuestos públicos que los tipos reducidos del IVA, por lo que conviene tenerlo en cuenta en el proceso de toma de decisiones. 
necesidades básicas, pero que se considere que merecen un trato preferente por otros motivos (por ejemplo, motivos culturales y educativos, transporte público).

En el 2008 se aprueban las siguientes directivas y con las siguientes finalidades ${ }^{6}$ :

- Directiva 2008/8/CE, de 12 de febrero de 2008, por la que se modifica la Directiva 2006/112/CE en lo relativo al lugar de la prestación de servicios, con la excepción de la parte de su contenido que debe incorporarse a la Legislación Nacional con efectos 1 de enero de 2015.

- Directiva 2008/9/CE, de 12 de febrero de 2008, por la que se establecen disposiciones de aplicación relativas a la devolución del impuesto sobre el valor añadido, prevista en la Directiva 2006/112/CE, a sujetos pasivos no establecidos en el Estado miembro de devolución, pero establecidos en otro Estado miembro.

- Directiva 2008/117/CE del Consejo de 16 de diciembre, por la que se modifica la Directiva 2006/112/CE, relativa al sistema común del impuesto sobre el valor añadido, a fin de combatir el fraude fiscal vinculado a las operaciones intracomunitarias.

Estas disposiciones de Derecho Comunitario hay que incorporarlas al Derecho Interno, y se necesita el correspondiente informe del Consejo de Estado según se prevé en el artículo 21 de la Ley Orgánica 3/1980, de 22 de abril del Consejo de Estado. A continuación, se lleva a cabo un análisis pormenorizado de los cambios:

\section{Lugar de prestación de servicios (Directiva 2008/8/CE)}

Se pretende hacer coincidir el lugar de consumo con el de sujeción al impuesto. Se establece un régimen general y otro especial. En cuanto al general, se distinguen: a) las operaciones empresariales (prestador y destinatario empresarios) en la que el gravamen se ubica en la jurisdicción de destino y b) operaciones en la que el destinarlo es un particular, en la que el gravamen se localizará en el lugar de origen. Asimismo, se prevé que se excluirá de la aplicación de este régimen los servicios con destinatarios de un país tercero, exceptuando los servicios entre profesionales residentes de Canarias, Ceuta y Melilla.

Este sistema general se aplica subsidiariamente a las previsiones especiales por la naturaleza del servicio o por la especial condición del destinatario del mismo:

1. Servicios de transporte: reglas generales

2. Actividades culturales, artísticas y deportivas: lugar de prestación de la actividad material

$6 \quad$ Ver informe del Consejo de Estado sobre el proyecto de ley sobre el IVA. 
3. Servicios por vía electrónica

4. Servicios de arrendamiento de medios de transporte a) a corto plazo: lugar de la puesta en posesión; b) a largo plazo: donde se realice el consumo

\section{Devolución del impuesto}

Se prevé un nuevo sistema de devolución que afectará a empresarios o profesionales establecidos en la Comunidad y se aplicará a partir de enero de 2010. Operará de la siguiente manera: los solicitantes habrán de enviar sus solicitudes de devolución del impuesto soportado en un Estado miembro distinto del que estaban establecidos por vía electrónica mediante los modelos de la página Web de su Estado de establecimiento. Esta solicitud se enviará del Estado de establecimiento al de devolución (en el que se ha soportado dicho gravamen).

\section{Fraude Fiscal (Directiva 2008/117/CE)}

Dicha Directiva modifica a la Directiva 2006/112/CE a fin de combatir el fraude fiscal vinculado a las operaciones intracomunitarias, ya que las entregas de bienes dentro de la Comunidad, establecidas en la anterior Directiva constituyen una de las causas de ese fraude. En concreto el plazo que transcurre entre una operación y el intercambio de información sobre la misma, suponía un obstáculo para el uso eficaz de dicha información a fin de luchar contra el fraude. Por ello lo que se pretende es que en el plazo de un mes la administración del Estado miembro en el que el IVA sea exigible disponga de información sobre las entregas intracomunitarias. Asimismo, tanto el proveedor como el adquiriente o destinatario deberán declarar las operaciones intracomunitarias para el mismo período impositivo.

\section{ASISTENCIA MUTUA Y ARMONIZACIÓN FISCAL}

La asistencia mutua se puede identificar con cooperación internacional, entendida ésta como una forma de actuación reconocida por el Derecho Internacional, en la que los Estados, por voluntad propia, deciden operar de manera conjunta para lograr objetivos comunes. Pero la sociedad internacional todavía no considera un imperativo común la lucha contra el fraude y la evasión fiscal. En un menor grado de desarrollo, puede entenderse la asistencia mutua como colaboración que supone que las administraciones nacionales actúan de manera concertada para conseguir unos fines determinados. Se puede decir que ésta es la asistencia más generalizada hoy en día. En ella se trata que una pluralidad de Estados, por un acto de libre voluntad, deciden prestar a otros Estados la ayuda necesaria en materia tributaria, la cual será unilateral y se confiere con la condición de reciprocidad.

En definitiva, la asistencia mutua comporta un conjunto de mecanismos que permiten la colaboración entre las Administraciones tributarias de distintos Estados. 
Una Comunicación de la Comisión de $2007^{7}$ señala que la armonización fiscal

\begin{abstract}
"consistirá en cualquier cambio que los países miembros de un mercado común realicen en los sistemas de la Hacienda Pública, que tiene la intención de conseguir los objetivos de esa unión económica. La justificación de la misma reside en que los sistemas fiscales de los países que integran la unión económica serán muy distintos y de lo contrario tendría lugar una serie de alteraciones que constituirían un obstáculo para la consecución de un mercado común si no se llevara a cabo esta armonización. El acuerdo de 1992 sobre el nivel actual de armonización se basó en dos consideraciones principales: 1) lo que se consideraba necesario para evitar el falseamiento de la competencia una vez creado el mercado interior y 2) la mayor armonización requerida para el denominado régimen «definitivo» del IVA basado en la imposición en origen".
\end{abstract}

Hay que recalcar que para la Unión Europea la armonización fiscal no es una finalidad, sino un instrumento para evitar que la disparidad de los sistemas tributarios de los Estados, sea de tal grado que cause graves perjuicios en el mercado interior europeo.

\title{
4. EL PRINCIPIO DE TERRITORIALIDAD EN EL IVA INTRACOMUNITARIO
}

Tal y como se ha dicho la creación del mercado interior implicó la supresión de las fronteras fiscales, así como una regulación nueva y específica a efectos del IVA. Fue también necesaria una mínima armonización de los tipos impositivos del impuesto y una adecuada cooperación administrativa entre los Estados miembros.

En España la adaptación fue tal, que incluso en la Exposición de Motivos de la ley 37/92 del IVA, se hace referencia a ello.

El Art.1 de la citada ley para analizar la naturaleza indirecta del impuesto señala que la misma "recae sobre el consumo". Continúa el artículo diciendo que gravará las siguientes operaciones:

- Las entregas de bienes y prestaciones de servicios efectuadas por empresarios o profesionales

- Las adquisiciones intracomunitarias de bienes

- Las importaciones de bienes

En relación al principio de territorialidad se puede hacer alusión a tres espacios:

- operaciones nacionales: las que tienen lugar dentro del territorio del Estado

7 Vid. COM (2007) 380 final. 
español, "incluyendo las islas adyacentes, el mar territorial hasta el límite de doce millas náuticas y el espacio aéreo correspondiente a dicho ámbito

- operaciones intracomunitarias: son las que se realizan dentro de la Unión Europea

- operaciones extracomunitarias: son las que implican un intercambio entre un Estado de la Unión Europea y un país extracomunitario

El IVA no se aplica en los territorios terceros, a saber:

- Isla de Helgoland, Territorio de Büsingen, Ceuta, Melilla, Livigno, Campione d'Italia y las aguas italianas del lago de Lugano (territorios igualmente excluidos del territorio aduanero de la $\mathrm{CE}$ )

- Monte Athos, Islas Canarias, departamentos franceses de ultramar, Islas Åland e Islas del Canal (territorios que sí forman parte del territorio aduanero de la CE)

De conformidad con las disposiciones del Tratado, el IVA tampoco se aplica a Gibraltar ni a la parte de Chipre que no está bajo control efectivo del Gobierno de la República de Chipre, regiones que son tratadas como territorios terceros.

El IVA sí se aplica en el Principado de Mónaco, la Isla de Man y las zonas de soberanía del Reino Unido en Akrotiri y Dhekelia, ya que no son considerados países terceros.

Desde el punto de vista espacial, el campo de aplicación del IVA es el del territorio del Estado. La característica de la territorialidad es una condición sine qua non para poder realizar la tasación espacial.

En lo que respecta al tratamiento del comercio exterior, a nivel comunitario los países han adoptado el principio de imposición en el país de destino, lo que implica gravar las importaciones y exonerar de impuestos a las exportaciones. La conclusión es que las importaciones estarán gravadas al igual que ocurre con los bienes y servicios como las producidas o prestadas dentro del Estado. En cambio, las exportaciones no están sujetas a impuestos, lo que implica la devolución de los impuestos que han gravado dichas mercancías dentro del territorio nacional, de conformidad con el principio de no discriminación. A veces a las exportaciones se las denomina como operaciones a tipo de gravamen cero, por no estar sujetas al pago de impuestos.

En relación con las operaciones intracomunitarias, se observa que desde el 1 de enero de 1993, a partir de la firma del Tratado de Maastrich en 1992, han desaparecido las fronteras fiscales entre los Estados de la Unión. Por tanto, se ha introducido una normativa comunitaria sobre el IVA en las operaciones intracomunitarias que establece que la transferencia de mercancías dentro de la Unión Europea no está sujeta a ninguna imposición fiscal aduanera.

Por tanto, el comercio intracomunitario ya no está constituido por lo que se podría entender como importaciones y exportaciones en un sentido técnico y 
estricto. Por consiguiente, en la actualidad se tratan y regulan a efectos del IVA como adquisiciones y suministros intracomunitarios.

La diferencia entre las importaciones procedentes de terceros países y las adquisiciones intracomunitarias, radica en que en las importaciones realizadas por terceros Estados es la aduana la encargada de gestionar el IVA y su imposición, cuando se produce el despacho aduanero.

En cambio, en el caso de las adquisiciones intracomunitarias no hay operaciones aduaneras y el impuesto se liquida directamente por el comprador en base a la factura emitida por el vendedor extranjero. Las adquisiciones intracomunitarias no son gravadas en el país del vendedor sino en el país de destino

\section{DEL RÉGIMEN TRANSITORIO AL DEFINITIVO}

\subsection{Régimen Transitorio}

Con la creación del Mercado Único, uno de los principales temas de debate fue cómo se llegaría al establecimiento de un régimen común del IVA en la Comunidad, el principal objetivo es la tributación en origen de las ventas realizadas en la Comunidad. Pero el tema no era un asunto fácil, puesto que para poder alcanzar dicha meta se tenía que dar satisfacción a dos problemas:

- La armonización de los tipos impositivos

- La asignación de los ingresos al Estado miembro de consumo

Sin embargo, para poder alcanzar dichos objetivos se requería de un horizonte temporal a largo plazo, por ello en 1989 el ECOFIN decidió establecer un régimen transitorio. De esta forma, se pretendía que se pudieran alcanzar los requisitos necesarios para el establecimiento del régimen definitivo.

El 1 de enero de 1993 a través de la Directiva 91/680/CEE, que modificó la Sexta Directiva de 1977, entró en vigor un nuevo régimen transitorio del IVA, el cual se aplicará a los intercambios intracomunitarios. La finalidad del mismo reside en el intento de responder a las exigencias de un mercado interior sin fronteras, a la vez que se respetan los márgenes de maniobra fiscales en los países miembros, y el control del impuesto. Las notas que definen este régimen son esencialmente tres:

1. Se mantiene el principio de destino con carácter general

2. Debido a la supresión de formalidades y controles aduaneros, se crea un sistema de intercambio automático de información y compensación entre las administraciones nacionales de datos relativos al valor de las entregas intracomunitarias de mercancías, (VAT Information Exchange System), o también llamado sistema VIES 
3. Los consumidores pueden pagar el IVA sobre los bienes adquiridos en otro Estado miembro en el país de origen

Por tanto, a modo de síntesis se puede decir que el régimen transitorio consiste en una entrega de bienes intracomunitaria, que quedará exenta, pero tendrá derecho a la deducción del IVA, y en contraposición una adquisición que estará sujeta a la tributación del impuesto. Este será el suceder normal de los intercambios intracomunitarios.

Los ingresos que se obtengan de la recaudación del IVA serán gestionados por el Estado miembro en cuyo territorio se lleve a cabo el consumo de los bienes vendidos. Esta tarea es complicada, por lo que se han desarrollado un número muy elevado de normas con la intención de determinar el lugar en que se deberán gravar las operaciones. Sin embargo, este modo de proceder obliga a los operadores a desglosar su volumen de negocios entre los diversos Estados miembros a los que corresponde su imposición, y contribuye a la fragmentación del Mercado. De este modo el IVA pierde su carácter objetivo, ya que el régimen fiscal que se reaplique dependerá de muchos factores, tales como el lugar en el que esté establecido el vendedor y el comprador, la situación fiscal del comprador y la naturaleza de los servicios prestados, entre otros.

Otra de las consecuencias negativas de este régimen es que no es acorde con el actual desarrollo del comercio internacional. Es totalmente inadecuado para el sistema de funcionamiento de las actuales empresas modernas.

Es evidente la complejidad del IVA y, por ello, la dificultad de alcanzar el régimen definitivo. La estructura del impuesto es común para todos los Estados miembros, pero todavía existen hechos distorsionadores, tales como que se mezcla el principio de tributación en origen y destino (por ejemplo, las ventas a distancias podrían tributar tanto en origen como en destino), así como la existencia de otros aspectos fundamentales que no han sido armonizados suficientemente, como los regímenes especiales.

El problema es que la UE está especialmente preocupada por los ingresos provenientes del IVA, ya que se puede decir que el IVA es el principal recurso económico a la hora de financiar el presupuesto comunitario. Además, los únicos responsables de recaudar este impuesto son los Estados.

En principio, el régimen explicado sólo se mantendría hasta el 31 de diciembre de 1996, pero el Consejo aún no ha establecido el régimen definitivo. Por tanto, el régimen transitorio continúa en vigor, aunque si es cierto que han sucedido modificaciones legislativas con la intención de ir perfeccionándolo progresivamente.

\subsection{Régimen Definitivo}

El régimen definitivo pretende que las transacciones intracomunitarias sean equivalentes a las internas. La segunda nota característica de este sistema es la 
necesidad de establecer un sistema de compensación que conforme al principio de tributación en origen.

En cuanto a la equiparación de las operaciones interiores y las comunitarias la idea es que el funcionamiento sea igual que en un mercado nacional. Se debe garantizar a los operadores que puedan actuar en todos los Estados miembros, y que no existan dificultades para ello. Las ventajas serían enormes, puesto que los operadores únicamente tendrían que trabajar con dos regímenes fiscales: el de las transacciones comunitarias y el que rija las transacciones de terceros países.

Estos años han servido para darse cuenta de que el someter a los operadores a la obligación de diferenciar sus ventas en función del lugar en el que éstas han sido realizadas es una tarea especialmente gravosa para ellos. La Comisión está de acuerdo con la simplificación del sistema, lo ideal es el no tener que hacer ya ninguna distinción en función del Estado miembro en que se realicen las transacciones.

Las consecuencias de esta configuración, en la que la actividad económica de cada agente dentro de la Comunidad quedará únicamente sujeta al impuesto de un solo Estado, traerán necesariamente consigo la necesidad de lograr la máxima armonización posible de los mecanismos impositivos. Por ello se debe tender a la utilización de tipos que sean lo más próximos posible.

El sistema propuesto presenta las siguientes ventajas:

1. Se equiparan las transacciones nacionales y las intracomunitarias

2. Se suprimen todas las excepciones a la norma general, con lo que se dificulta el fraude

3. Solamente tendrá competencia de supervisión una sola administración fiscal. De esta forma se reduce la carga de trabajo, y se podrán dedicar a supervisar con mayor intensidad allí donde sea necesario

4. Facilidad para el sujeto pasivo, y además tendrá derecho a exigir que se le detalle cuáles son sus obligaciones, y que se le administre de forma justa y correcta el impuesto

5. Se elimina la circulación de bienes libres de IVA

Según con el nuevo sistema, se ha de hacer referencia a la responsabilidad colectiva y al énfasis en la cooperación que se persigue en el mismo. La responsabilidad individual se sustituye por la colectiva, es decir, que todos los Estados miembros tendrán la misma responsabilidad en la obtención de los ingresos fiscales, ya que la actuación que realice cada uno va a repercutir directamente en el presupuesto nacional de cada uno de los demás. Por esta razón, todo el sistema debe basarse en la asistencia y confianza mutua entre los Estados.

En cuanto a la cooperación administrativa se puede decir que cobrará mayor importancia. A la hora de controlar las transacciones se tendrá en cuenta el lugar en el que esté censado el sujeto pasivo, aunque materialmente la transacción se desarrolle en otro Estado miembro. Por tanto, para poder obtener esta información será imprescindible esta cooperación entre los Estados. Asimismo, se exigirá una 
actuación entre los Estados miembro que se podrá equiparar a la que hoy existe dentro de cada Estado. Esta cooperación es consecuencia directa la responsabilidad colectiva.

Parece claro que el mercado interior funcionaría mejor con un régimen de tributación en origen, ya que se reducirían los costes para las empresas y se dificultaría el fraude fiscal porque la estabilidad de los ingresos fiscales sería mayor. De momento se sigue con el régimen transitorio, por ello, la Comisión estima que sería conveniente para mejorar en el corto plazo la simplificación y modernización de las normas existentes, así como una aplicación más uniforme de las disposiciones actuales y que la cooperación administrativa entre los Estados tome impulso.

Por ejemplo, muchos Estados miembros han decidido gravar los servicios postales. Esta circunstancia refleja que ya no se respeta el principio de neutralidad en este sector. Por ello la modificación del sistema, que impone a los servicios postales tributar el IVA ayudará a esta modernización.

Otro de los puntos clave es el tratamiento del comercio electrónico, la radiodifusión y la teledifusión. En un principio la regla es que éstas serían gravadas como servicios y la imposición se realizaría en función de la jurisdicción en donde fuese prestado el servicio. Sin embargo, la Comisión quiere modificar este sistema, de forma que los servicios electrónicos se graven con el IVA de la Unión Europea cuando se presten para su consumo dentro de la misma, y que estén exentos cuando el consumo sea fuera de la UE. El mercado electrónico vive en un continuo desarrollo y crecimiento, por lo que las administraciones fiscales lo deberán tener muy en cuenta, actuar y adaptarse con la misma rapidez que éste evoluciona. Se deberá procurar la protección de los intereses públicos. Para la imposición de este régimen será necesario el establecimiento de medios y modalidades de control que faciliten la cooperación administrativa.

En los últimos años muchas de las actividades que pertenecían al sector público se han privatizado, por ello será oportuno adaptar el régimen del IVA aplicable a estas prestaciones. Otro punto para tener en cuenta deberá ser el régimen aplicable a las subvenciones con la intención de que éstas también queden armonizadas a nivel comunitario.

En cuanto a las normas relativas a la entrega de bienes será necesario el readaptar algunas de ellas para cubrir las necesidades del comercio intracomunitario. Por ejemplo, en la venta a distancia, el régimen transitorio ha demostrado que será necesario que el operador cumpla por propia iniciativa sus obligaciones de declarar y pagar para garantizar la imposición en destino. Por ello podrían llevarse a cabo modificaciones respecto a los límites máximos de imposición, la cual podría ir acompañada de un establecimiento de intercambio de información de manera automática entre los Estados.

La situación de descontento con el régimen transitorio parece generalizada, y son muchas las deficiencias de su funcionamiento. El cambio al régimen definitivo es ya una auténtica necesidad. De esta forma, bajo el principio de tributación en origen 
los beneficios serían manifiestos, ya que todos los operadores sacarían partido de la supresión de las fronteras fiscales característica del Mercado Único.

A modo de conclusión, los pilares sobre los que se pretende erigir el régimen definitivo son:

1. El impuesto debe conservar su carácter neutral

2. Prevenir y evitar el fraude fiscal

3. Los Estados miembros deberán mantener sus ingresos físcales

4. La reducción de los trámites administrativos por parte de las empresas y de la administración, para procurar una aplicación más sencilla del impuesto

\subsection{El Sistema de Compensación}

Se puede decir que el tema de la implantación de un mecanismo de compensación del IVA es uno de los más problemáticos y que más debate genera entre los países miembros de la Unión Europea.

Al ser el IVA un impuesto indirecto sobre el consumo, la facturación total del mismo corresponde al país en el que tiene lugar el consumo final del bien, sin tener en cuenta el lugar de fabricación.

En la actualidad si un producto es vendido fuera de las fronteras nacionales, en términos fiscales, dicha operación se encuentra exenta de IVA en origen, pero se mantiene el derecho a la deducción de los IVA soportados.

Así, en un sistema en el que prevalece el principio de imposición según el destino, el IVA facturado en la exportación se aplica en el lugar y al tipo correspondiente al país de destino final de la misma. En un sistema contrario como el que se pretende aplicar, cuando el principio de destino se sustituye por el del origen, el lugar donde se repercute el IVA a la exportación no coincide con el lugar de consumo del bien y, por tanto, tampoco coincide con el lugar donde corresponde la recaudación por dicho impuesto.

Por consiguiente, debido a razones de tipo presupuestario $\mathrm{y}$, porque nunca o casi nunca en la práctica tendrá lugar un equilibrio en los flujos comerciales intracomunitarios entre todos y cada uno de los países, es necesario establecer un sistema de compensación o "clearing" que permita que las cuotas repercutidas e ingresadas en un país miembro en concepto de exportación sean devueltas al resto de los Estados miembros en los que las cuotas impositivas van a ser deducidas y en los que va a tener lugar el consumo final del bien o servicio.

\section{CONCLUSIONES}

En primer lugar, desde el Tratado de Roma hasta nuestros días han cambiado mucho los objetivos respecto a la armonización de la imposición indirecta. En el ámbito del IVA la realización del mercado interior, que sustituyó al mercado común, fue un avance significativo en la eliminación de obstáculos y de las fronteras fiscales 
pero, por el contrario, fue una fuente de nuevos problemas en el ámbito del fraude fiscal.

En segundo lugar, al ser el IVA no sólo un impuesto nacional armonizado, sino una fuente importante para el sistema de recursos propios del presupuesto comunitario, el problema del fraude fiscal en el IVA deja de ser un problema exclusivamente nacional y se convierte en un problema comunitario. Este hecho explica el interés de la Comisión europea por promover acciones preventivas y correctivas del fraude fiscal en el IVA, entre la que destaca la asistencia entre Administraciones tributarias de los Estados miembros en la Unión Europea.

Por último, la aprobación la aprobación de la Sexta Directiva constituye la norma más importante en materia de armonización fiscal en el IVA, pues con ella quedaron establecidas las reglas básicas y uniformes para la determinación de una base imponible común, que era necesaria para fijar la participación de la Comunidad en la recaudación del IVA en los Estados miembros.

Las modificaciones que ha sufrido esta Sexta Directiva para conseguir alcanzar el principio de tributación en origen no se han podido realizar debido a la imposibilidad de consensuar un sistema de compensación, que permita que las cuotas repercutidas e ingresadas en un país miembro en concepto de exportación sean devueltas al resto de los Estados miembros en los que las cuotas impositivas van a ser deducidas y en los que va a tener lugar el consumo final del bien o servicio.

Pero se han dado pasos significativos en el avance de la asistencia mutua, como son el sistema VIES. Éste es un sistema informático de intercambio de información entre los Estados miembros de la Unión Europea sobre el IVA en las transacciones intracomunitarias. La existencia de este sistema es debida a la supresión de las fronteras interiores comerciales y fiscales como consecuencia de la creación del Mercado Único, que exigió sustituir los controles físicos en las fronteras por un intercambio de información entre las autoridades fiscales sobre las operaciones intracomunitarias realizadas por los sujetos pasivos del IVA.

\section{REFERENCIAS}

Albi, E.; Contreras, C.; González-Páramo, J.M. y ZUBIRI, I. (2009): Economía Pública I y II, Ariel, Barcelona.

Albi, E. (2001): "Armonización fiscal europea: balance de situación", Papeles de Economía Española, No. 87.

Alonso González, L.M.; Corona Ramón, J.F. y Valera Tabueña, F. (1997): La armonización fiscal en la Unión Europea. CEDECS, Barcelona.

Devereux, M.P. y Griffith, R. (1998): “Taxes and the location of production: evidence from a panel of U.S. multinationals", Journal of Public Economics, Vol. 68, No. 3. 
Eijffinger, S.C.W.; Huizinga, H.P. y Lemmen, J.J.G. (1998): "Short-term and longterm government debt and non-resident interest withholding taxes", Journal of Public Economics, Vol. 68, No.3.

López García, M.A. (1998): "On welfare and revenue effects of induced tax harmonization", Economic Letters, 60.

Mangas Martín, A. y LIÑÁN NOGUERAS, D.J. (2007): Instituciones y Derecho de la Unión Europea. Tecnos, Madrid.

Mata Sierra, Ma. T. (1996): La armonización fiscal en la Unión Europea. 2a ed. Lex Nova, Valladolid.

Victoria Sánchez, A. (2008): Memento práctico IVA. Francis Lefebvre, Madrid. 